\title{
European Thyroid Association (ETA) and Thyroid Federation International (TFI) Joint Position Statement on the Interchangeability of Levothyroxine Products in EU Countries
}

\author{
Eric Fliers ${ }^{a}$ Barbara Demeneix ${ }^{b}$ Ashok Bhaseen ${ }^{c}$ Thomas H. Brix ${ }^{d}$ \\ a Department of Endocrinology and Metabolism, Amsterdam University Medical Centers, Location AMC, \\ Amsterdam, The Netherlands; ' Evolution des Régulations Endocriniennes, Département "Adaptation du Vivant", \\ UMR 7221 Muséum National d'Histoire Naturelle/CNRS, Paris, France; 'Montreal, QC, Canada; ${ }^{\mathrm{d}}$ Department of \\ Endocrinology and Metabolism, Odense University Hospital, Odense C, Denmark
}

\section{Keywords}

Levothyroxine products · Health issues · European Thyroid Association · Thyroid Federation International

\section{Abstract}

Several European countries have seen major health issues after a switch from one levothyroxine brand to another, as well as following the introduction of several levothyroxine formulation changes. While the relationship between these health issues and brand or formulation changes merits further investigation, the current position statement on behalf of both health-care providers and patients summarizes recent events in several European countries and provides a number of recommendations to limit the burden for patients, so as to prevent increased health-care consumption and health-care expenses in this context.

(C) 2018 European Thyroid Association Published by S. Karger AG, Basel

A. Bhaseen: on behalf of the Thyroid Federation International. E. Fliers, B. Demeneix, T.H. Brix: on behalf of the Executive Committee of the European Thyroid Association.

\section{KARGER}

(๑) 2018 European Thyroid Association

Published by S. Karger AG, Basel

E-Mail karger@karger.com

www.karger.com/etj

\section{Introduction}

For the treatment of hypothyroidism, desiccated thyroid made from animal thyroid glands remained the mainstay of therapy until the 1970s. Levothyroxine came to market in the 1960s in the form of sodium Lthyroxine, which was better absorbed than the free-acid thyroxine. Levothyroxine is a drug with a narrow therapeutic index, which is the range of doses at which a medication is effective without unacceptable adverse events. Drugs with a narrow therapeutic index have a slender window between their useful doses and those at which they produce adverse toxic effects. As a consequence, whenever a pharmaceutical company decides to introduce a new levothyroxine formulation, great care should be taken to guarantee that bioequivalence and dosage form proportionality between the marketed formulation and the new formulation. In addition, generic levothyroxine may be substituted for brand-name levothyroxine only if the recommended bioequivalence limits are met. Equally important, the manufacturers should inform health professionals and the users, in this case users of levothyroxine (accepting that the manu- 
facturers are not allowed to contact the users on an individual level, this could be done by advertising in printed and web-based platforms), of these changes and how to deal with them.

In 2004, the US Food and Drug Administration (FDA) approved first-time generic levothyroxine sodium for the treatment of hypothyroidism, thereby rejecting a citizen petition filed in 2003 regarding bioequivalence of levothyroxine sodium tablets. This situation raised concern and resulted in the publication of a joint statement by the American Thyroid Association, the Endocrine Society, and the American Association of Clinical Endocrinologists [1]. The statement included serious concerns about the FDA's method for determining bioequivalence as it was potentially flawed for endogenously produced substances and included a recommendation that physicians as well as patients should be educated about these concerns. Under a policy of allowing generic levothyroxine substitution, the necessity of more frequent thyroid function testing was anticipated, and physicians caring for patients on levothyroxine therapy were advised to alert patients that their medication may be switched at the pharmacy. Additional advice given was to encourage patients to ask to remain on their current levothyroxine preparation and to make sure that patients understand that after receiving a new preparation (from one brand to another, from a brand to a generic product, or from a generic product to another generic product), they will need to be retested with a serum TSH within 6 weeks to determine if they needed dose adjustment.

Several European countries have seen serious issues regarding the interchangeability of levothyroxine products over the past years. The existing recommendations in the USA have not been taken into account in these instances, and several levothyroxine formulation changes have been introduced without prior consultation of health-care professionals and patient organizations. In the Netherlands, there was an increasing shortage of the most commonly used levothyroxine brand Thyrax ${ }^{\circledR}$ between February 2016 and April 2017, resulting in a forced brand switch for 350,000 patients. A subsequent evaluation based on 2 national databases containing thyroid test results showed that many patients received oversupplementation as a consequence of the switch. The Thyrax shortage resulted from the planned change of the production facility by the manufacturer (Aspen). In France, the manufacturer of Levothyrox ${ }^{\circledR}$ (distributed as Euthyrox ${ }^{\circledR}$ in Belgium and other EU countries) decided to switch to a new formulation to comply with the most stringent potency specifications. Although a

Interchangeability of Levothyroxine Products in EU Countries scientific publication by Merck [2] claimed that the new formulation meets potency specification and bioequivalence guidelines, a marked increase in the number of reported side effects was noted in France. This resulted in a moratorium on the introduction of the new formulation in other European countries pending reevaluation as judged by the national Medicine Evaluation Boards. In fall 2008, the manufacture of Eltroxin ${ }^{\circledR}$ (GlaxoSmithKline [GSK]), at that time the only supplier of levothyroxine in Denmark, changed their formulation in order to prolong its shelf life. Although the new Eltroxin formulation meets the potency specifications, the Danish Medicine Agency received a huge increase in reported side effects within the first year after this change.

These various national issues will be briefly summarized below.

\section{Netherlands}

In February 2016, it became clear that there was a shortage of Thyrax tablets, initially regarding the $25-\mu \mathrm{g}$ tablets only but later the additional potencies (100 and $150 \mu \mathrm{g})$ as well. Of note, the Dutch Medicine Evaluation Board had transferred the trade license for Thyrax from MSD (Oss, The Netherlands) to Aspen Pharma Trading Limited in Ireland in 2014. In the same year, a technical transfer project was started to facilitate the reallocation of production to Aspen Bad Oldesloe (ABO) $\mathrm{GmbH}$, a new production facility in Oldesloe, Germany. In 2015, it became clear that Thyrax ABO tablets showed a more rapid degradation than Thyrax MSD tablets. This led to various unsuccessful actions by Aspen to secure the availability of Thyrax on the market.

As a result, 350,000 patients using Thyrax in the Netherlands (i.e., $70 \%$ of the total number of levothyroxine users) were forced to switch to another formulation, principally levothyroxine Teva ${ }^{\circledR}$ or Euthyrox. The number of reported side effects increased, and many family doctors and internists were confronted with patients mentioning health problems after switching to the new formulation (Netherlands Institute for Health Services Research, or NIVEL; www.nivel.nl/nl/thyrax). The Dutch Endocrine Society together with the Dutch thyroid patient organization Schildklier Organisatie Nederland ( $\mathrm{SON}$ ) issued a general advice to check serum TSH concentration 6 weeks after any brand change, and the issue was covered by several national media. The Dutch Ministry of Health, Welfare and Sport provided a small 
subsidy to run a telephone support service by SON. Following an initiative by SON and the Dutch Endocrine Society, the Ministry provided a small grant to 2 Dutch health-care institutions (NIVEL and the Institute for Drug Outcomes Research PHARMO) to investigate the consequences of the Thyrax shortage in terms of laboratory results (2 separate databases) and online questionnaires. The research projects were coordinated by a sounding board group comprising representatives of all stakeholders (Dutch Endocrine Society, SON, NIVEL and PHARMO, Medicine Evaluation Board, The Netherlands Pharmacovigilance Centre Lareb, and The Royal Dutch Pharmacists Association).

The NIVEL and PHARMO reports were published in April 2017 (https://www.schildklier.nl/onderzoek-naaroverstap-thyrax-duotab-afgerond). It appeared that 53\% of the patients using $>100 \mu \mathrm{g}$ daily $(50,000 \mu \mathrm{g}$ in total) showed biochemical signs of oversupplementation, clearly in excess of background observations before the switch had taken place (Fliers et al., in preparation). In addition, $30 \%$ of the patients experienced more health problems than before the switch. It should be mentioned that $25 \%$ experienced fewer health problems. The initial advice to the patients was confirmed, but now with the additional remark that for patients using $>100 \mu \mathrm{g}$ daily, an a priori dose reduction should be considered when switching from Thyrax to levothyroxine Teva or Euthyrox. For the patient organization SON, these results strengthened their earlier position, i.e., to be strongly opposed to a forced brand switch for patients using levothyroxine preparations. This was explicitly stated in a letter to the Dutch parliament dated February 21, 2017, on behalf of various patient platforms on the forced switch of pharmaceutical products for nonmedical reasons (https://www. schildklier.nl/nieuws/43-nieuws/393-petitie-over-gevolgen-preferentiebeleid-en-teva-tekort-op-zelfde-dag). In their final report dated June 1, 2016, the Dutch Ministry of Health, Welfare and Sport (Inspectie Gezondheidszorg en Jeugd) concluded that Aspen Pharma Trading Limited had underestimated the transfer of the production of Thyrax to another location and should have taken more care to ensure the availability of Thyrax to fulfill patients' needs (https://www.rijksoverheid.nl/documenten/kamerstukken/2017/09/07/kamerbrief-over-igz-onderzoekthyrax). The Dutch Medicine Evaluation Board approved the production process at the new location on March 30, 2017.

\section{France}

In France, as of March 2017, 2.6 million patients were being treated with Merck's Levothyrox according to data from the French Agence Nationale de Sécurité des Médicaments (ANSM). A switch was made to the new Merck formulation (with mannitol as opposed to lactose) as of late March/April 2017. The justification given by the ANSM was the need for tighter specification (95-105\%) over the whole shelf life, as for other thyroxine products (however, according to patient associations, the ANSM documents requesting the formulation change have yet to be released). In January 2018, 17,310 reports of adverse effects had been received by the national site for drug surveillance (BNPV, Base National de Pharmacovigilance [http://ansm.sante.fr/content/download/115249/.../Rapport_Levothyrox_CT-30-01-2018.pdf. This report updated a previous one published in October 2017: http:// ansm.sante.fr/content/download/111053/.../RapportLevothyrox-PV-oct-2017.pdf]). These adverse effects included headaches, insomnia, depression, anxiety, vertigo, joint pain, hair loss, and muscular fatigue and were estimated to have affected $0.75 \%$ of the patients treated. Among the adverse effects, for those with TSH levels reported, approximately $60 \%$ displayed normal TSH levels, $20 \%$ were indicative of hypothyroidism, and $15 \%$ had hyperthyroidism. As to serious adverse events (for instance death, incapacity, or requiring hospitalization), 474 cases were reported, although as yet in none of the cases can the role of the new formulation be either incriminated or exonerated.

As the formulation change might go unnoticed in view of very similar packaging, practitioners and pharmacies were instructed to inform patients of the need to check their TSH within 6 weeks if they noticed any change in their overall health status. However, this information was not always given.

A number of official statements originally suggested that the adverse events were largely fueled by social media. The two patient associations in France underlined the lack of information from practitioners to patients (Vivre Sans Thyroïde and Association des Maladies de la Thyroïde). This lack of information contrasts with the situation in Belgium, where the consequences for patients due to a change in supply in 2014 was followed more closely, and adverse effects events were better dealt with.

The actions taken by the two French patient organizations, and by various journalists, led to three decisions by the French Ministry of Health. First, the data assessing bioequivalence should be made public. Second, for a lim- 


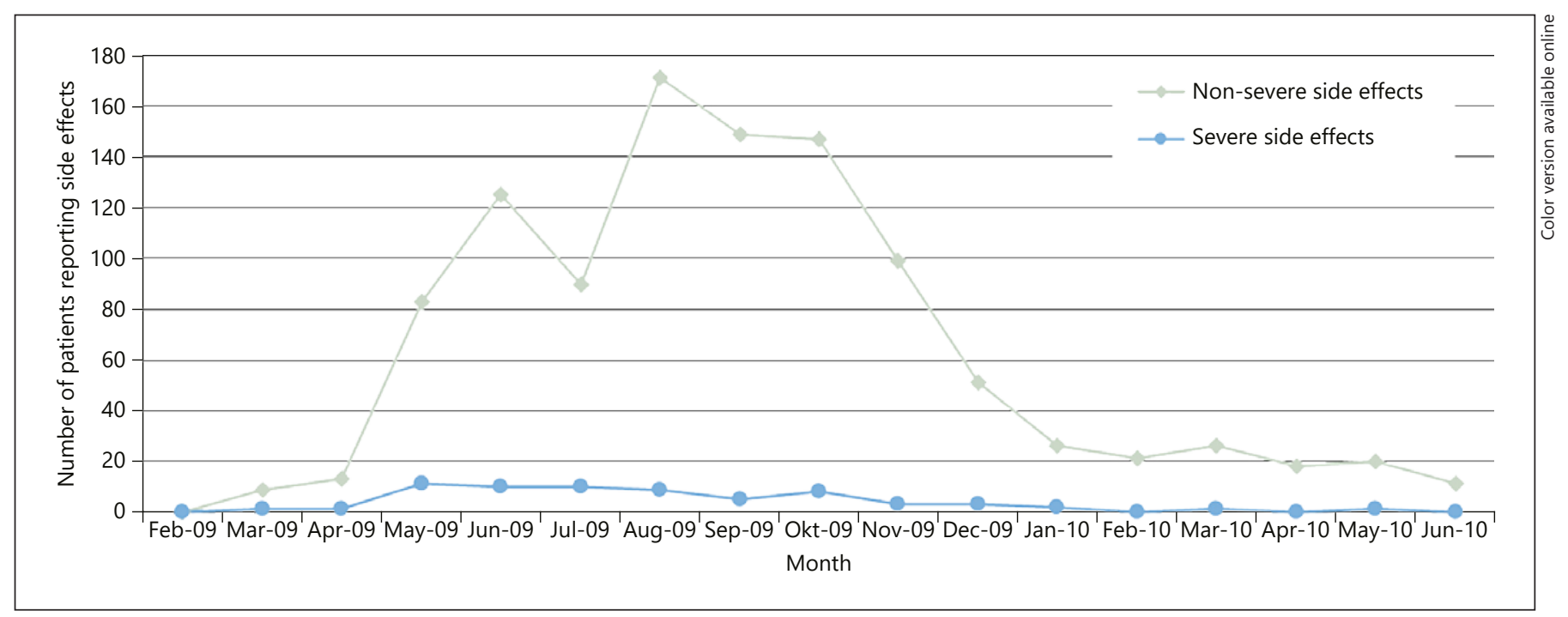

Fig. 1. Number of reported side effects of Levothyroxine in Denmark in 2009 and 2010. Data obtained from the Danish Medicines Agency. Status: by ultimo 2009, 919 patients had reported 5,015 possible side effects.

ited time span, the old formulation of Levothyrox will be made available to French patients who request it, though stocks are currently insufficient to meet the demand. Third, two other brands, L-thyroxin Henning ${ }^{\circledR}$ (Sanofi) and Thyrofix ${ }^{\circledR}$ (Unifarm), will now be available on the French market, as will one liquid formulation, primarily intended for infants.

\section{Denmark}

In 2008 , there were approximately 80.000 patients in Denmark treated with levothyroxine [3]. Since GSK had a monopoly position, all these subjects were treated with a GSK product, Eltroxin. This product was well tolerated as reflected by the fact that the Danish Medicines Agency only received approximately 1 report per month on side effects. By the end of 2008, GSK decided to switch to a new formulation to prolong the shelf life. Although the new formulation meets potency specification guidelines and is bioequivalent, a growing number of patients began to complain of intolerance and several unspecific health problems after starting on this "new drug." The problem was covered by the Danish thyroid patient organization and subsequently by national media. Meanwhile, the numbers of reported side effects exploded, from approximately 1 per month to around 100 per month during 2009 (Fig. 1). At the end of 2009, more than 900 patients

Interchangeability of Levothyroxine Products in EU Countries had reported $>5,000$ possible side effects. Most of the reported side effects were suggestive of either hyper- or hypothyroidism, but only very few was classified as severe. As a consequence, the Danish Thyroid Association together with The Danish Medicine Agency issued a general advice to monitor the TSH concentration 4-6 weeks after switching to the product with the new formulation. Another consequence was that GSK lost their monopoly status, and Merck decided to launch Euthyrox on the Danish Market at the end of December 2009. The number of reported side effects began to decline during late fall 2009 and returned to baseline numbers by the end of June 2010 (Fig. 1).

\section{Conclusions}

1. Several European countries have seen major health issues after a switch from one levothyroxine brand to another, as well as following the introduction of several levothyroxine formulation changes.

2. Although it is not possible to ascertain what proportion of these health issues are biologically related to the formulation change, the issues include increased prevalence of side effects as well as increased prevalence of biochemical signs of inadequate dosing, and result in increased health-care consumption and health-care expenses. 
3. Testing bioequivalence does not guarantee continued euthyroidism after a formulation change of levothyroxine.

4. In at least 3 European countries, formulation changes have been introduced by manufacturers without adequate communication with health-care professionals and patient organizations.

\section{Recommendations}

1. Patients should be maintained on the same formulation/brand name of levothyroxine. If a change is necessary, a blood test after 6 weeks is recommended to determine, if any adjustment to dosage is required.

2. Manufacturers should carefully prepare the introduction of a formulation change together with representatives of relevant stakeholders (health-care professionals, national Endocrine Society, Medicine Evaluation Board, Pharmacovigilance Centre, Pharmacists Association, national or - if not applicable international patient organizations) to prevent insufficient communication and coordination.

3. The preparation of a formulation change should include a monitoring plan to become active immediately after introduction.

4. Authorities should define the required levothyroxine potency specifications in an unambiguous way.

5. The method for determining the bioequivalence of levothyroxine preparations should be reevaluated.

\section{Disclosure Statement}

The authors have no conflicts of interest to disclose.

\section{References}

1 American Thyroid Association; Endocrine Society; American Association of Clinical Endocrinologists: Joint Statement on the U.S. Food and Drug Administration's decision regarding bioequivalence of levothyroxine sodium. Thyroid 2004;14:486.

2 Gottwald-Hostalek U, Uhl W, Wolna P, Kahaly GJ: New levothyroxine formulation meeting $95-105 \%$ specification over the whole shelf-life: results from two pharmacokinetic trials. Curr Med Res Opin 2017;33: 169-174.

3 Cerqueira C, Knudsen N, Ovesen L, Laurberg P, Perrild H, Rasmussen LB, Jørgensen T: Doubling in the use of thyroid hormone replacement therapy in Denmark: association to iodization of salt? Eur J Epidemiol 2011;26: 629-635. 